\title{
Death Anxiety in Palliative Care
}

\author{
Dein Simon* \\ University College London and Durham University, United Kingdom
}

\begin{abstract}
Received: December 14, 2013; Accepted: January 27, 2014; Published: January 29, 2014
"Corresponding author: Dein Simon, University College London and Durham University, United Kingdom, Tel: 127-982-7262; Fax: 127-941-4058; Email: s.dein@ucl.ac.uk
\end{abstract}

Death anxiety can be defined as anxiety related to the awareness of death. As anthropologist Ernest Becker [1] argues, humans are unique in that they must learn to adapt to the finitude of their lives. Becker's work resulted in the development of terror management theory (TMT), which argues that while humans strive for self-preservation, they are also aware of the inevitability of death [2]. According to this approach, when people are reminded of their mortality, their need for structure and meaning intensifies, resulting in an enhanced focus on personally and culturally valued goals. How different groups adapt to death anxiety is highly influenced by cultural factors [3]. But death anxiety is not necessarily negative. Sligte D, et al. [4] found that death anxiety may actually enhance creativity and be a novel driver for inventing new theories of existence.

Surveys have shown that $50-80 \%$ of terminally ill patients have concerns or troubling thoughts about death; only a minority achieve an untroubled acceptance of death [5]. While a number of death anxiety scales exist [6], they are not routinely used in palliative care. We know little about the factors contributing to death anxiety in this population, how it is experienced, expressed, its impact on quality of dying and general distress, and the efficacy of strategies to alleviate it. Nevertheless the data that are available suggest that death anxiety negatively impacts upon quality of life and may predispose to depression [7] and (paradoxically) a desire to hasten death [8]. In cancer patients Gonen G, et al. [9] found that death anxiety (as measured by the Templer Death Anxiety Scale) was associated with anxiety, depressive symptoms, and beliefs about what will happen after death. Axis I psychiatric diagnosis, pain scores, and negative beliefs about what will happen after death were found to be higher in patients experiencing death anxiety than in those not experiencing it . Furthermore life expectancy was perceived as shortened in those patients suffering from death anxiety. In a recent study Neel C, et al. [10] found that death anxiety in patients with advanced cancer is common and determined by the interaction of individual factors, family circumstances and physical suffering. The authors suggest that multidimensional interventions that incorporate these and other factors may be most likely to be effective in alleviating such death-related distress.

Two qualitative studies on early breast cancer [11] and brain tumours [12] highlighted the depth of distress produced by death anxiety in such patients. Addressing religious or spiritual issues may be recommended for allaying distress but such support may not commonly occur [13-18]. Although some studies have examined interventions to reduce existential distress [19-21], these have not specifically addressed death anxiety.

There is some evidence that nurse's own death anxiety may have a negative impact on their own ability to care for dying patients [22]. The authors examined fifteen quantitative studies published between 1990 and 2012 exploring nurses' own attitudes towards death. Three key themes identified were:

i) Nurses' level of death anxiety;

ii) Death anxiety and attitudes towards caring for the dying

iii) Death education was necessary for such emotional work.

Of interest the studies indicated that the level of death anxiety exhibited by nurses working in palliative care, general, oncology, renal and community was not high with younger nurses consistently reporting higher levels. In some studies inverse relationships were found between nurse's attitudes towards their own death and their attitudes towards caring for dying patients.

To date there has been no work specifically addressing the management of death anxiety in palliative care populations. Furer P \& Walker JR [23] describe the efficacy of deploying CBT (cognitive behaviour therapy) to allay death anxiety in clients suffering from health anxiety and this may provide a model for those working with end of life individuals. They emphasize that avoidance of death is one of the most common ways of dealing with fears of death. In a preliminary study of the use of acceptance commitment therapy Sussman JC \& Liu W [24] asked students to watch a short video of a young person with acute lymphoid leukaemia experiencing death anxiety receiving either ACT (acceptance commitment therapy) or CT (cognitive therapy). The students were then required to evaluate the impact of the treatment. The authors propose that palliative care patients expressing death anxiety may benefit from either ACT or CT for death anxiety. They underscore the fact that future research is needed to explore the usefulness of each approach. 
Death anxiety remains an under researched area in palliative care. Future research should contribute on predisposing factors, its impact on psychiatric morbidity and the efficacy of psychotherapeutic interventions in its alleviation.

\section{References}

1. Becker E (1973) The denial of death. New York Free Press.

2. Pyszczynski T, Greenberg J, Solomon S (1999) A Dual-Process Model of Defense Against Conscious and Unconscious Death-Related Thoughts: An Extension of Terror Management Theory. Psychol Rev 106(4): 835-845.

3. Ma-Kellams C, Blascovich J (2012) Enjoying life in the face of death: East-West differences in responses to mortality salience. J Pers Soc Psychol 103(5): 773-786.

4. Sligte D Nijstad BA De Dreu C (2013) Leaving a legacy neutralizes negative effects of death anxiety on creativity. Pers Soc Psychol Bull 39(9): 1152-1163

5. Cherny $\mathrm{N}$ (2000) The treatment of suffering in patients with advanced cancer: In Chochinov $\mathrm{H}$ and Breitbart W (eds.), Handbook of Psychiatry in Palliative Medicine. Oxford University Press.

6. Thorson JA, Powell FC (1992) A revised death anxiety scale: Death Studies 16(6): 507-521.

7. Cella DF, Tross S (1987) Death anxiety in cancer survival: A preliminary cross-validation study. J Pers Assess 51(3): 451-461.

8. Kelly B, Burnett P, Pelusi D, Badger S, Varghese F, et al. (2003) Factors associated with the wish to hasten death: a study of patients with terminal illness. Psychol Med 33(1): 75-81.

9. Gonen G, Kaymak SU, Cankurtaran ES, Karslioglu EH, Ozalp E, et al. (2012) The factors contributing to death anxiety in cancer patients. J Psychosoc Oncol 30(3):347-58.

10. Neel C, Lo C, Rydall A, Hales S, Rodin G (2013) Determinants of death anxiety in patients with advanced cancer BMJ Support Palliat Care bmjspcare-2012-000420Published Online First: 22 August 2013 doi:10.1136/bmjspcare-2012-000420

11. Dein S, Stygal J, Martin P (2006). The use and expectations of prayer in women with breast cancer' Healing Ministry 13(4): 23-31.
12. Adelbratt S, Strang P (2000) Death anxiety in brain tumour patients and their spouses. Palliat Med 14(6): 499-507.

13. Dein S, Abbas SQ (2005) The stresses of volunteering in a hospice: a qualitative study Palliative Medicine 19: 58-64.

14. Abbas Q, Dein S (2011) The difficulties assessing spiritual distress in palliative care patients: a qualitative study. Mental Health, Religion and Culture 14(4): 341-52.

15. King MB, Koenig HG (2009) Conceptualising spirituality for medical research and health service provision. BMC Health Services Research $9(1): 116$

16. King M, Leavey G (2010) Invited Commentary: Spirituality and religion in psychiatric practice: why all the fuss? The Psychiatrist bulletin 34: 190-193.

17. Leavey G, King M (2007) The devil is in the detail: partnerships between psychiatry and faith-based organisation. Br J Psychiatry 191: 97-98.

18. Dein S (2005) Culture and Cancer Care: Anthropological Insights in Oncology. Buckingham: Open University Press.

19. Miller DK, Chibnall JT, Videen SD, Duckro PN (2005). SupportiveAffective Group Experience for Persons with Life-Threatening Illness: Reducing Spiritual, Psychological, and Death-Related Distress in Dying Patients. J Palliat Med 8(2): 333-343.

20. Chochinov HM, Hack T, Hassard T, Kristjanson LJ, McClement S, et al. (2005) Dignity therapy: A novel psychotherapeutic intervention for patients near the end of life. J Clin Oncol 23(24): 5520-5525.

21. Bloch S, Kissane D (2000) Psychotherapies in psycho-oncology: an exciting new challenge. Br J Psychiatry 177:112-116.

22. Peters L, Cant R, Payne S, O'Connor M, McDermott F, et al. (2013) How death anxiety impacts nurses' caring for patients at the end of life: A review of literature. Open Nurs J 7:14-21.

23. Furer P, Walker JR (2008) Death anxiety: A cognitive-behavioral approach. Journal of Cognitive Psychotherapy 22(2): 167-182.

24. Sussman JC, Liu W (2013) Perceptions of two therapeutic approaches for palliative care patients experiencing death anxiety. Palliat Support Care 6: 1-10. 